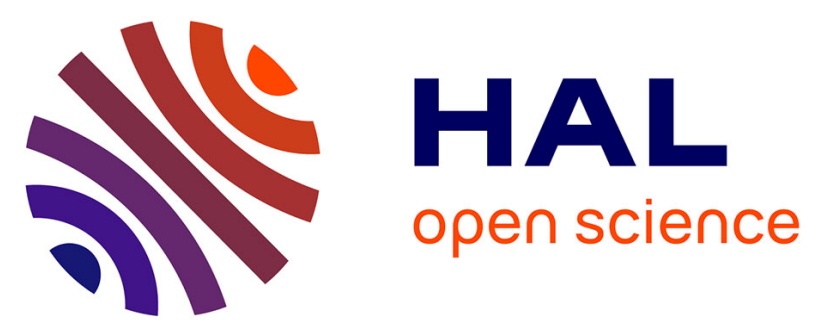

\title{
Ankle Brachial Index (ABI) predicts 2-year mortality risk among older adults in the Republic of Congo: The EPIDEMCA-FU study
}

Harielle Samba, Maëlenn Guerchet, Bébène Ndamba-Bandzouzi, Gilles Kehoua, Pascal Mbelesso, Iléana Desormais, Victor Aboyans, Pierre-Marie Preux, Philippe Lacroix

\section{To cite this version:}

Harielle Samba, Maëlenn Guerchet, Bébène Ndamba-Bandzouzi, Gilles Kehoua, Pascal Mbelesso, et al.. Ankle Brachial Index (ABI) predicts 2-year mortality risk among older adults in the Republic of Congo: The EPIDEMCA-FU study. Atherosclerosis, 2019, 286, pp.121-127. 10.1016/j.atherosclerosis.2019.05.013 . hal-02173508

\section{HAL Id: hal-02173508 \\ https://hal-unilim.archives-ouvertes.fr/hal-02173508}

Submitted on 25 Oct 2021

HAL is a multi-disciplinary open access archive for the deposit and dissemination of scientific research documents, whether they are published or not. The documents may come from teaching and research institutions in France or abroad, or from public or private research centers.
L'archive ouverte pluridisciplinaire HAL, est destinée au dépôt et à la diffusion de documents scientifiques de niveau recherche, publiés ou non, émanant des établissements d'enseignement et de recherche français ou étrangers, des laboratoires publics ou privés.

\section{(ㅇ)(1) $\$$}

Distributed under a Creative Commons Attribution - NonCommerciall 4.0 International 


\section{Ankle Brachial Index (ABI) predicts 2-year mortality risk among older adults in the Republic of Congo: the EPIDEMCA-FU study}

Harielle Samba ${ }^{1,2}$, Maëlenn Guerchet ${ }^{1,2,3}$, Bébène Ndamba-Bandzouzi ${ }^{1,4}$, G. Kehoua ${ }^{1,2}$; Pascal Mbelesso ${ }^{1,5}$, Ileana Desormais ${ }^{1,2,6}$, Victor Aboyans ${ }^{1,2,7}$ Pierre-Marie Preux ${ }^{1,2,8}$, Philippe Lacroix ${ }^{1,2,6}$

1- INSERM, U1094, Tropical Neuroepidemiology, Limoges, France

2- Univ. Limoges, UMR_S 1094, Tropical Neuroepidemiology, Institute of Neuroepidemiology and Tropical Neurology, CNRS FR 3503 GEIST, F-87000 Limoges, France

3- King's College London, Centre for Global Mental Health, Health Service and Population Research Department, Institute of Psychiatry, Psychology \& Neuroscience, De Crespigny Park, London, SE5 8AF, United Kingdom

4- Department of Neurology, Brazzaville University Hospital, Brazzaville, Republic of Congo

5- Department of Neurology, Amitié Hospital, Bangui, Central African Republic

6- Department of Vascular Medicine, Limoges University Hospital, Limoges, France

7- Department of Cardiology, Limoges University Hospital, Limoges, France

8- CHU, CEBIMER, Limoges, France

Corresponding author: Maëlenn Guerchet

INSERM, UMR_S U1094, Tropical Neuroepidemiology

Faculté de Médecine, 2 rue du Dr Marcland

87025 Limoges cedex, France

Tel: (0033)5 55435820

Fax: (0033)5 55435821

Email: maelenn.guerchet@unilim.fr 
Keywords: Peripheral artery disease, Mortality, Ankle-brachial index, Older adults, sub-Saharan Africa, epidemiology. 


\section{Abstract}

Background and aims: Peripheral artery disease (PAD) is known to be associated with mortality in high income countries but no data regarding Sub-Saharan Africa (SSA) populations are documented. This study is aimed at assessing the prognostic value of the Ankle Brachial Index (ABI) among older adults in the Republic of Congo.

Methods: Congolese subjects $\geq 65$ years were included in a longitudinal population-based survey (EPIDEMCA-FU). Demographic, biological, and clinical data were collected at baseline. PAD was defined by an $\mathrm{ABI} \leq 0.90$. Information on mortality was collected from key informants in participants' households. Cox proportional hazard models, adjusted for traditional and cardiovascular risk factors, were fitted to evaluate the association between an $\mathrm{ABI} \leq 0.90$ and death.

Results: 1029 participants were recruited at baseline. ABI measurement was obtained from 927 participants, of whom $17.4 \%$ presented an $\mathrm{ABI} \leq 0.90$. During a 2-year follow-up, a total of $83(9.1 \%)$ deaths were recorded. Mortality was higher in the low-ABI group with 23 deaths (14.7\%) vs. 57 $(7.8 \%)$ and $3(12.0 \%)$, respectively among those with $0.90<\mathrm{ABI}<1.4$ and $\mathrm{ABI} \geq 1.40(p=0.039)$. After adjustment, an $\mathrm{ABI} \leq 0.90$ was associated with an increased risk of mortality ( $\mathrm{HR}=1.86$; 95\% CI 1.043.87). Mortality was also independently associated with increasing age (HR=1.05; 95\% CI 1.02-1.09), dementia $(\mathrm{HR}=2.73$; 95\% CI 1.15-8.05), alcohol use (HR=0.51; 95\%CI 0.29-0.88) and female sex (HR=0.37; 95\%CI 0.19-0.72).

Conclusions: In this study, a low ABI predicted an increased mortality risk among older people. ABI may represent a simple and inexpensive tool to identify older people at high risk of death in SSA. 


\section{Introduction}

With population ageing, the burden of non-communicable diseases, such as cardiovascular diseases (CVDs), is increasing in sub-Saharan Africa (SSA) [1,2]. Among people living in high-income countries, those with lower-extremities peripheral artery disease (PAD) are at increased risk of subsequent cardiovascular events [3,4] and death [5,6,7]. Older adults are the most exposed and affected group $[8,9]$. Due to the lack of symptoms, PAD is frequently misdiagnosed [5,10]. Therefore, screening of asymptomatic patients with PAD might be an efficient method to identify those at an increased risk of death [10]. PAD can easily and reliably be detected at low cost by the measurement of the Ankle-Brachial Index (ABI) [4,11]. In high-income countries, PAD defined by an $A B I \leq 0.90$ is associated with an increased risk of cardiovascular events and mortality $[6,13,14,15]$.

In SSA, the prevalence of PAD is equal to or higher than what is observed in high income countries, exceeding 50\% in some high-risk populations [16]. Despite the growing burden of PAD in this region [17], knowledge about $\mathrm{ABI}$ and its prognostic value remains scarce [7, 16, 18]. Information regarding the prognostic value of ABI in elderly people living in SSA may help identify high-risk individuals, in order to focus restrained healthcare resources on them. To our knowledge, there are no previous population-based studies investigating the prognostic value of ABI among older adults in SSA.

Therefore, the aim of this study is to assess the prognostic value of the ABI measurement as a screening tool for PAD, to predict mortality risk among Congolese older adults. Using $\mathrm{ABI}$ as a screening tool $(\mathrm{ABI} \leq .90)$ [17], we previously estimated the prevalence of PAD in this population at $17.4 \%$. We hypothesised that, despite the specific socio-economic context in this low-income country, a low ABI measurement would remain a significant predictor of mortality.

\section{Patients and methods}

\section{Study design and participants}

The EPIDEMCA-FU (Epidemiology of Dementia in Central Africa - Follow-Up) is a longitudinal population-based study carried out in the Republic of Congo [19]. It is part of a research programme studying the Epidemiology of Dementia in Central Africa (EPIDEMCA), which started in 2011 [20].

Adults aged 65 and over were included at baseline and then followed-up over a 2-year period (20122014). Baseline data collection has been described elsewhere [20]. Essentially, sampling methods differed between urban and rural areas. Due to logistical and financial constraints, door-to-door knocking was carried out in each district constituting the rural catchment area (Gamboma's main 
districts). In case of an inhabitant's absence during the day of screening, houses were revisited at least twice. A random sampling, proportional to the size of each main subdivision of the city, took place in the urban site. This was to ensure the representation of Brazzaville's diverse population. For each main subdivision, a district was randomly chosen. The procedure in each district remained consistent: a door to-door survey was conducted in a random direction, starting from the district chief's house, until the number of participants allocated to each subdivision was reached. If the number of participants was not reached in the first district, the procedure was applied in another random district belonging to the same subdivision. In both sites, the only exclusion criteria were refusal or the presence of severe diseases with a short-term high risk of death. A sample size was projected in order to estimate the prevalence of dementia. The minimum number of subjects needed to detect a prevalence of $5 \%$, with a precision of $2 \%$, was 456 subjects (EpiInfo 6.04, Epiconcept). The study population consisted of 1,029 participants living in Congo: 529 participants (51.4\%) in Gamboma (rural area) and $500(48.6 \%)$ in Brazzaville (urban area).

Data about ABI and other variables (age, sex, living area, cardiovascular risk factors, and life habits) used for analysis were collected during the EPIDEMCA baseline survey [20].

Throughout each stage of the programme (baseline and follow-up), written consent (or oral in case of illiteracy) was obtained from the participants and/or their relatives. The study was approved by the Congolese ethical committee CERSSA (Comité d'Ethique de la Recherche en Sciences de Santé) and by a French ethics review board (Comité de Protection des Personnes Sud-Ouest Outre Mer).

\section{Baseline data}

\section{PAD: measurement, definition and diagnosis}

Measurement protocol and ABI calculation were following the American Heart Association (AHA) guidelines [11]. Measurements of upper- and lower-extremity blood pressures were performed after at least 30 minutes of rest. Systolic blood pressures (SBP) were measured in both arms and legs, with the subject in the supine position. Hand-held Doppler ultrasound devices (Dopplex 900, Huntleigh Healthcare Ltd, Cardiff, UK) were used to measure SBP of posterior tibial and dorsal pedis arteries bilaterally. ABI measurement was not performed on participants with leg ulcers, fractures, sores, edema, hemiplegia, or other reasons preventing ABI measures. In agreement with recommendations, $\mathrm{ABI}$ in each leg was calculated by dividing the highest pressure between posterior tibial and dorsalis pedis arteries by the highest arm pressure. The $\mathrm{ABI}$ of the individual was the lowest $\mathrm{ABI}$ amongst the two legs. An $\mathrm{ABI} \leq 0.90$ was used to define $\mathrm{PAD}$ while an $\mathrm{ABI} \geq 1.40$ defined poorly compressible ankle arteries, a condition mostly associated with medial calcinosis and also associated with increased mortality [11]. If an ABI was $\leq 0.90$ while the other was $>1.40$, the subject was categorised with an 
$\mathrm{ABI} \leq$ 0.90. Thus, we defined three groups of participants according to their $\mathrm{ABI}$ : normal group $(0.90<\mathrm{ABI}<1.40)$, PAD group $(\mathrm{ABI} \leq 0.90)$ and poorly compressible ankle arteries group $(\mathrm{ABI} \geq 1.40)$.

\section{Questionnaire and measures (variables)}

At baseline, a questionnaire was administrated to all participants prior to physical examination. The structured interview was conducted by trained investigators in local languages (Lingala, Kituba and Lari) or in French. The questionnaire collected information about participants' sociodemographic status (age, sex, living area, marital status, education level and occupational activities), lifestyle (tobacco and alcohol use) and cardiovascular risk factors. History of hypertension, diabetes, and myocardial infarction were investigated by self-report.

Physical examination included body weight, height, blood pressure, and waist circumference measurements. In case of an elevated blood glucose level, according to WHO recommendation's (above $126 \mathrm{mg} / \mathrm{dL}$ if the fasting period $>2$ hours or above $200 \mathrm{mg} / \mathrm{dL}$ in non-fasting participants) [23] and/or self-reported treatment, participants were categorised as having diabetes. Hypertension was defined by self-reported treatment or in case of high blood pressure, as defined by the WHO [24] (i.e. brachial SBP at rest $\geq 140 \mathrm{mmHg}$ and/or diastolic blood pressure (DBP) $\geq 90 \mathrm{mmHg}$ ). Body Mass Index (BMI) was calculated by dividing weight (in $\mathrm{kg}$ ) by the square of height (in meters). BMI categories were defined according to WHO classification's: underweight (BMI<18.5); normal $(18.5 \leq \mathrm{BMI} \leq 24.9)$; overweight $(25.0 \leq \mathrm{BMI} \leq 29.9)$; obese (BMI $\geq 30)$ [25]. Abdominal obesity was defined according to the recommended waist circumference thresholds for abdominal obesity in SSA (94 cm for men and $80 \mathrm{~cm}$ for women) [26]. Total cholesterol and C-Reactive Protein (CRP) dosages were performed on plasma aliquots using standard procedures (Biochemistry department, Limoges University Hospital on Cobas automaton). Hypercholesterolemia was defined by total cholesterol >5.3 $\mathrm{mmol} / \mathrm{L}$. Tobacco and alcohol use were categorised as dichotomic variables (respectively current and former users $v s$. never, and sometimes and regularly $v s$. none).

Dementia was diagnosed using a two-stage design [20] and defined according to DSM-IV criteria [21]. Petersen's criteria was used for Mild Cognitive Impairment diagnosis (MCI) [22].

\section{Follow-up data}

The outcome collected was all-cause mortality within 2 years of the follow-up. In case of death or recurrent absence, information about the older person's vital status was obtained from relatives. If participants moved away between baseline and follow-up visits, they were traced and contacted at their new addresses. All participants whose vital statuses could not be filled accurately and reliably were considered as lost to follow-up. When it was possible, the date of death was recorded. If only the month of death was known, an arbitrary date set at the $15^{\text {th }}$ of the month was considered. History of 
illness before death and probable cause of death were recorded using the WHO disease definition. Vital status was defined as a dichotomic variable: alive / deceased.

\section{Statistical analyses}

Categorical and continuous variables were respectively presented by numbers (percentages) and means (standard deviations). For descriptive analyses, $\mathrm{Chi}^{2}$ or Fisher's exact tests were used when appropriate to compare categorical variables while the Student's t-test was used for continuous variables after checking the normality.

Cox proportional hazard models, with estimations of hazard ratios (HR) and their 95\% confidence intervals (CI), were performed to assess the association between ABI categories and 2-year mortality. After a univariate analysis, the multivariate model included age, sex, residency area, cognitive status, and lifestyle and cardiovascular covariates: tobacco and alcohol use, diabetes, hypertension, BMI, hypercholesterolemia, and abdominal obesity. Covariates were then selected through a backward stepby-step regression, removing progressively variables which were not reaching statistical significance. This model was fitted using 2-year vital status (death/alive) as the dependent variable and baseline $\mathrm{ABI}$ groups as the main independent variable. Interaction between an $\mathrm{ABI}$ and sex was also tested in this model (introducing a multiplicative term ABI* sex). Statistical significance level was fixed at 0.05 .

Data management and statistical analyses were performed using Stata (version 10.1, Stata-Corp, College Station, Texas, United States).

\section{Results}

The baseline study population consisted of 1,029 older adults (mean age $73.8 \pm 6.8$ years): 403 (39.2\%) males and 626 (60.8\%) females. Due to missing ABI measurement, 102 (9.9\%) participants were excluded. Excluded participants were older and more likely to live in the urban area. They were less likely to have hypertension, but more likely to have dementia (Supplementary Table 1). For this study, analyses were therefore based on 927 participants: 161 (17.4\%) with $\mathrm{ABI} \leq 0.90,740$ (79.8\%) with $0.90<\mathrm{ABI}<1.4$ and $26(2.8 \%)$ with $\mathrm{ABI} \geq 1.40$ (Fig. 1).

Participant's characteristics, according to baseline ABI measurements, are displayed in Table 1. Participants with $\mathrm{ABI} \leq 0.90$ at baseline were more likely to be older $(p=0.009)$, female $(p=0.038)$, overweight $(p=0.057)$, to have hypertension $(p<0.001)$ and hypercholesterolemia $(p=0.057)$. Often, they lived in an urban area $(p=0.037)$ and were less likely to have formal education $(p=0.040)$. 
Notably, we found no significant differences regarding rates of diabetes, smoking and alcohol use (Table 1).

After 2 years of follow-up, vital status was obtained for all except 15 participants (1.6\%) (Fig. 1). Hence, these participants were excluded from survival analysis. These participants were not different from the other participants regarding baseline data (data not shown).

During the 2-year period of follow-up, we recorded 83 (9.1\%) deaths: 23 (14.7\%) among those with $\mathrm{ABI} \leq 0.90,57(7.8 \%)$ among those with $0.90<\mathrm{ABI}<1.40$ and $3(12.0 \%)$ among those with $\mathrm{ABI} \geq 1.40$. Cause of the death remained unknown in $53 \%$ of the cases, whilst cardiovascular diseases were reported as a cause of death in $36 \%$. The proportion of death was more important in the low-ABI group compared to the normal group $(p=0.039)$.

In univariate analysis, a low ABI was associated with an increased 2-year mortality risk. After adjustment, $A B I \leq 0.90$ was still associated with increased mortality risk. People with $A B I \leq 0.90$ had about two-fold higher risk of death $(\mathrm{HR}=1.86$; 95\% CI 1.04-3.87, $p=0.044)$ compared to those with a normal ABI. Mortality was also independently associated with increasing age (HR=1.05; 95\% CI 1.02-1.09; $p=0.002)$ and the presence of dementia (HR=2.73; 95\% CI 1.15-8.05; $p=0.007)$. A lower risk of mortality was associated with alcohol use (HR=0.51; 95\%CI 0.29-0.88; $p=0.017)$ and female sex $(\mathrm{HR}=0.37$; 95\%CI 0.19-0.72; $p<0.003)$ (Table 2). No significant interaction was found between $\mathrm{ABI}$ and sex when mortality was considered as dependent variable $(p=0.106)$, ruling out a different effect of a low ABI on mortality according to sex.

\section{Discussion}

Our study confirms our hypothesis that $\mathrm{PAD}$, defined as $\mathrm{ABI} \leq 0.90$, is associated with an increased risk of death in this older Congolese population. This association remained significant after adjustments and was not different according to sex.

Our findings are consistent with those reported in other studies conducted in high-income countries [5, 6, 27]. In the Edinburgh cohort study, 1592 men and women aged from 55 to 74 years were randomly selected from the registers of general practices and followed-up for over 12 years. The relative risks of all-cause mortality associated with $\mathrm{ABI} \leq 0.90$ varied after adjustment on sex, age and major cardiovascular risk factors from 1.42 (95\% CI 1.15-1.74) to 1.14 (95\%CI, 0.91-1.43), respectively [28]. In the Cardiovascular Health Study (CHS), the relative risk for 6-year total mortality was 1.62 (95\% CI 1.24-2.12) for CVD-free participants aged $\geq 65$ years [29]. In a primary care population, Diehm et al. described a 2-fold increased risk of death associated with a low ABI [6]. When Heald et al. reviewed available surveys on PAD and mortality risk, the pooled estimates for relative risk associated 
with low-ABI were 2.35 (95\% CI 1.66-3.32) after adjustment on age and sex, and 1.60 (95\% CI 1.321.95) when the adjustment was extended to cardiovascular risk factors, respectively [5]. Nevertheless, in the 5 studies included in the analysis, duration of follow-up ranged from 4 to 12 years. To resolve the uncertainties related to different follow-up periods, a meta-analysis of time-to-event outcomes estimated an ABI-associated all-cause mortality risk between 1.18 and 5.06 [30]. Furthermore, analyses based on data from sixteen population cohort studies showed that a low ABI $(<$ or $\leq 0.90)$ was associated with approximately twice the 10-year total mortality [31]. No interaction suggesting a difference in risk of mortality between men and women with a low PAD was found in this population. Unfortunately, studies investigating the prognostic value of the AnkleBrachial Index were not reporting on this potential difference, it is therefore not possible to compare our results to the literature. Considering the 2-year follow-up time, the mortality risk estimated in our older population with PAD seems to be slightly higher compared to other population-based studies [5]. Most of these studies showed an estimated mortality relative risk below 1.7, for follow-ups ranging from 4 to 12 years [5]. Authors considered that the higher risk may be related to a higher mean age of the population, as evidence from epidemiological data showed increasing prevalence of PAD $(\mathrm{ABI} \leq 0.90)$ with age: around $10 \%$ by the age of 65 and as high as $25 \%$ after 85 [32]. Our overall population was at a high risk, with a mean age (73.8 \pm 6.8 years) exceeding the average life-expectancy in this country (64.1 years according to the World Bank data in 2015 [33]). Furthermore, prevalence of diabetes and hypertension was high, at $11 \%$ and $67 \%$ respectively. These characteristics may contribute to the high mortality rate in the cohort: the overall mortality was $9 \%$ after 2 years. In most studies, the annual mortality rate was lower than in our survey, between 1.18 and 5.06 [30]. The Republic of Congo, as well as most SSA countries, has limitations in financial resources and access to treatment or medical facilities (in rural areas), which can hinder medical care and lead to increased mortality. The stronger association between PAD and mortality may be partly explained by a lower quality of care, risk factors control and the socio-economic situation. The ethnic influence on PAD prevalence was previously documented in the US population $[29,34,35]$, the condition being more prevalent in African-Americans. In the Cardiovascular Health Study [29], a second cohort of 687 African-American participants was enrolled and followed-up during 2 years. The main characteristics of this population were very similar to our cohort. The proportion of AfricanAmerican participants with low ABI and no history of clinical PAD was 16.5\% (as compared to $14.7 \%$ in our study). After 2 years, death rates were $17.1 \%$ and $3.8 \%$ in case of low or normal ABI, respectively. The prevalence of high $\mathrm{ABI}(\geq 1.40)(2.8 \%)$ in our study is concordant with data from high income countries studies $(1.4 \%-2.8 \%)$ [30,36]. In these studies, high ABI was associated with increased mortality $[37,38]$. This association was not statistically significant in our study. Although the limited number of participants with high $\mathrm{ABI}$ and shorter time of follow-up may explain these results. 
The present study presents several limitations. As expected in a longitudinal study, fifteen participants (1.6\%) were lost to follow-up. However, compared with previous cohort studies conducted in SSA, the study achieved an excellent follow-up rate. As these participants had similar characteristics to those followed-up, a systematic bias is unlikely. Our follow-up period (2 years) was short compared to comparable studies that had follow-ups up to 11 years. In spite of this, we were able to show a significant effect very similar to the one described in the second CHS cohort [29]. Yet, as we were unable to evaluate accurately all causes of death, our results are limited to the overall mortality risk. Medical care during follow-up could be a source of confounding, but due to limited access to healthcare, we are confident that this observation bias is unlikely here. Furthermore, we must acknowledge that the self-reported nature of some information represents another limitation of our study, with a possibility of a significant amount of wrong or missing information due to the lack of awareness or access to healthcare facilities in this context. Nevertheless, all the main variables used in our multivariate model were measured, limiting the use of self-reported covariates to description only. Finally, as data on triglyceride levels was not available in our population, the estimation of the metabolic syndrome, an important predictor of cardiovascular diseases, was not possible and adjustments of our models were limited in this regard.

Based on our results, measurement of ABI enables to identify a subgroup of population with an $\mathrm{ABI} \leq 0.90$, who is at high risk of mid-term ( 2 years) mortality. $\mathrm{ABI}$ is a simple and rapid test, which could be performed by trained healthcare workers in the general population. However, our study is limited to individuals aged $\geq 65$ years and the results can therefore not be extrapolated to younger people. Considering that, like anywhere else, the prevalence of PAD booms after this age limit [39], this tool might be particularly useful in low- and middle-income countries with limited medical resources to identify people at high risk. Further research is therefore required to evaluate the input of ABI measurement in population-based prevention programmes in sub-Saharan Africa.

Conflict of interest: The authors declared they do not have anything to disclose regarding conflict of interest with respect to this manuscript.

Financial support: EPIDEMCA was supported by a French National Research Agency grant (ANR09-MNPS-009-01). EPIDEMCA-FU was supported by the AXA Research Foundation (2012 Project - Public Health Institute (Inserm) - PREUX Pierre-Marie) and by the APREL grant from Limoges Hospital University.

Author contributions: HS, BNB, GK, PMB, MG, JFD, PMP and PL were involved in the study design and data collection. HS, MG and PL prepared the first draft. Other authors reviewed the 
manuscript, provided further contributions and suggestions. All authors read and approved the final manuscript.

Acknowledgements: The authors would like to thank all participants and their families; Marien Ngouabi University and its School of Health Sciences in Brazzaville (Congo), and the Health ministry of the Republic of Congo, for their moral support; town halls, mayors, and district's chiefs of Gamboma and Brazzaville for their collaboration; interviewers working for the programme, and the Neurology department's staff of the hospital of Brazzaville for their assistance; Mr Romuald Batantou (Brazzaville University) for his help in data collection and Mr Liam Sherratt (King's College London) for reading and correcting the manuscript. 


\section{References}

1- Dalal S, Beunza JJ, Volmink J, Adebamowo C, Bajunirwe F, et al: Non-communicable diseases in sub-Saharan Africa: what we know now. Int. J. Epidemiol. (2011) 40, 885-901.

2- Fowkes FGR, Rudan D, Rudan I, Aboyans V, Denenberg JO, et al: Comparison of global estimates of prevalence and risk factors for peripheral artery disease in 2000 and 2010: a systematic review and analysis. Lancet Lond. Engl. (2013) 382, 1329-1340.

3- Doobay AV, and Anand SS. Sensitivity and specificity of the ankle-brachial index to predict future cardiovascular outcomes: a systematic review. Arterioscler. Thromb. Vasc. Biol. (2005) 25, 14631469.

4- Espinola-Klein C, Rupprecht HJ, Bickel C, Lackner K, Savvidis S, et al: Different calculations of ankle-brachial index and their impact on cardiovascular risk prediction. Circulation. (2008) 118, $961-$ 967.

5- Heald CL, Fowkes FGR, Murray GD, Price JF, and Ankle Brachial Index Collaboration Risk of mortality and cardiovascular disease associated with the ankle-brachial index: Systematic review. Atherosclerosis. (2006) 189, 61-69.

6- Diehm C, Lange S, Darius H, Pittrow D, von Stritzky B, et al: Association of low ankle brachial index with high mortality in primary care. Eur. Heart J. (2006) 27, 1743-1749.

7- Mensah GA, Roth GA, Sampson UkA, Moran AE, Feigin VL, et al: Mortality from cardiovascular diseases in sub-Saharan Africa, 1990-2013: a systematic analysis of data from the Global Burden of Disease Study 2013. Cardiovasc. J. Afr. (2015) 26, S6-S10.

8- Vogt MT, Wolfson SK, and Kuller LH. Lower extremity arterial disease and the aging process: a review. J. Clin. Epidemiol. (1992) 45, 529-542.

9- Guerchet M, Aboyans V, Nubukpo P, Lacroix P, Clement JP, et al: Ankle Brachial Index as a marker of cognitive impairment and dementia in general population: A systematic review. Artherosclerosis (2011) 2, 251-257.

10- Lin JS, Olson CM, Johnson ES, and Whitlock EP. The ankle-brachial index for peripheral artery disease screening and cardiovascular disease prediction among asymptomatic adults: a systematic evidence review for the U.S. Preventive Services Task Force. Ann. Intern. Med. (2013) 159, 333-341. 
11- Aboyans V, Criqui MH, Abraham P, Allison MA, Creager MA, et al: Measurement and interpretation of the ankle-brachial index: a scientific statement from the American Heart Association. Circulation (2012) 126, 2890-2909.

12- Leng GC, Fowkes FG, Lee AJ, Dunbar J, Housley E, et al: Use of ankle brachial pressure index to predict cardiovascular events and death: a cohort study. BMJ (1996) 313, 1440-1444.

13- Jönsson B, and Skau T. Ankle-brachial index and mortality in a cohort of questionnaire recorded leg pain on walking. Eur. J. Vasc. Endovasc. Surg. (2002) 24, 405-410.

14- Criqui MH, Ninomiya JK, Wingard DL, Ji M, and Fronek A. Progression of peripheral arterial disease predicts cardiovascular disease morbidity and mortality. J. Am. Coll. Cardiol. (2008) 52, $1736-1742$.

15- Vogt MT, Cauley JA, Newman AB, Kuller LH, and Hulley SB. Decreased ankle/arm blood pressure index and mortality in elderly women. JAMA (1993) 270, 465-469.

16- Johnston LE, Stewart BT, Yangni-Angate H, Veller M, Upchurch GR, et al: Peripheral Arterial Disease in Sub-Saharan Africa: A Review. JAMA Surg. (2016) 151, 564-572.

17- Desormais I, Aboyans V, Guerchet M, Ndamba-Bandzouzi B, Mbelesso P, et al : Prevalence of peripheral artery disease in the elderly population in urban and rural areas of Central Africa: the EPIDEMCA study. Eur. J. Prev. Cardiol. (2014) 22,1462-72.

18- Sampson UKA, Fowkes FGR, McDermott MM, Criqui MH, Aboyans V, et al: Global and regional burden of death and disability from peripheral artery disease: 21 world regions, 1990 to 2010. Glob. Heart (2014) 9, 145-158.

19- Samba H, Guerchet M, Ndamba-Bandzouzi B, Mbelesso P, Lacroix P, et al: Dementia-associated mortality and its predictors among older adults in sub-Saharan Africa: results from a 2-year follow-up in Congo (the EPIDEMCA-FU study). Age Ageing (2016). 45,681-687.

20- Guerchet M, Mbelesso P, Ndamba-Bandzouzi B, Pilleron S, Desormais I, et al : Epidemiology of dementia in Central Africa (EPIDEMCA): protocol for a multicentre population-based study in rural and urban areas of the Central African Republic and the Republic of Congo. SpringerPlus (2014) 3, 338.

21- WHO, World Health Organization: Definition and diagnosis of diabetes mellitus and intermediate hyperglycemia: report of a WHO/IDF consultation. 2006. 
22- WHO, World Health Organisation Silent killer, global public health crisis. WHO/DCO/WHD/2013.2. In A Global Brief on Hypertension. World Health Organization, Geneva; 2013.

23- World Health Organization: Physical status: the use and interpretation of anthropometry. Report of a WHO Expert Committee. Technical Report Series No. 854. World Health Organization, Geneva; 1984.

24- Alberti KG, Eckel RH, Grundy SM, Zimmet PZ, Cleeman JI, et al: Harmonizing the metabolic syndrome: a joint interim statement of the International Diabetes Federation Task Force on Epidemiology and Prevention; National Heart, Lung, and Blood Institute; American Heart Association; World Heart Federation; International Atherosclerosis Society; and International Association for the Study of Obesity. Circulation (2009) 120, 1640-1645.

25- American Psychiatric Association (2003). In DSM-IV-TR Manuel diagnostique et statistique des troubles mentaux: Texte révisé, (Paris: Masson), p. 1064.

26- Petersen RC. Mild cognitive impairment as a diagnostic entity. J Intern Med. (2004) 256,183-194.

27- Newman A, Siscovick DS, Manolio TA, Polak J, Fried LP, et al: Ankle-arm index as a marker of atherosclerosis in the Cardiovascular Health Study. Cardiovascular Heart Study (CHS) Collaborative Research Group. Circulation (1993) 88, 837-845.

28- Lee AJ, Price JF, Russell MJ, Smith FB, van Wijk MCW, and Fowkes, F.G.R. Improved prediction of fatal myocardial infarction using the ankle brachial index in addition to conventional risk factors: the Edinburgh Artery Study. Circulation (2004) 110, 3075-3080.

29- Newman AB, Shemanski L, Manolio TA, Cushman M, Mittelmark M, et al: Ankle-arm index as a predictor of cardiovascular disease and mortality in the Cardiovascular Health Study. The Cardiovascular Health Study Group. Arterioscler Thromb Vasc Biol. (1999) 19:538-45.

30- Hajibandeh S, Hajibandeh S, Shah S, Child E, Antonio GA, et al: Prognostic significance of ankle brachial pressure index: A systematic review and meta-analysis. Vascular. (2016) 25, 208-22. 31- Ankle Brachial Index Collaboration, Fowkes FG, Murray GD, Butcher I, Heald CL, et al: Ankle brachial index combined with Framingham Risk Score to predict cardiovascular events and mortality: a meta-analysis. JAMA. (2008) 300:197-208.

32- Aboyans V, Lacroix P, Laskar M. The level of knowledge of risk factors for peripheral arterial disease also depends on subjects' individual clinical situations. Can J Cardiol. (2009) 25:545. 
33- The Wolrd Bank Data. Life expectancy at birth, total (years). Derived from male and female life expectancy at birth from United Nations Population Division. World Population Prospects. Available at https://data.worldbank.org/indicator/SP.DYN.LE00.IN?locations=CG.

34- Allison MA, Ho E, Denenberg JO, Langer RD, Newman AB, et al : Ethnic-specific prevalence of peripheral arterial disease in the United States. Am J Prev Med. (2007) 32, 328-33.

35- Zheng ZJ, Rosamond WD, Chambless LE, Nieto FJ, Barnes RW, et al: Lower extremity arterial disease assessed by ankle-brachial index in a middle-aged population of African Americans and whites: the Atherosclerosis Risk in Communities (ARIC) Study. Am J Prev Med. (2005) 29:42-49.

36- Resnick HE, Lindsay RS, McDermott MM, Devereux RB, Jones KL, et al: Relationship of high and low ankle brachial index to all-cause and cardiovascular disease mortality: the Strong Heart Study. Circulation. (2004) 109, 733-739.

37- O'Hare AM, Katz R, Shlipak MG, Cushman M, and Newman AB. Mortality and cardiovascular risk across the ankle-arm index spectrum: results from the Cardiovascular Health Study. Circulation. (2005) 113, 388-393.

38- Resnick HE, Foster GL. Prevalence of elevated ankle-brachial index in the United States 1999 to 2002. Am J Med. (2005) 118:676 -9.

39- Guerchet M, Aboyans V, Mbelesso P, Mouanga AM, Salazar J, et al: Epidemiology of Peripheral Artery Disease in Elder General Population of Two Cities of Central Africa: Bangui and Brazzaville. Eur. J. Vasc. Endovasc. Surg. (2012) 44, 164-169. 


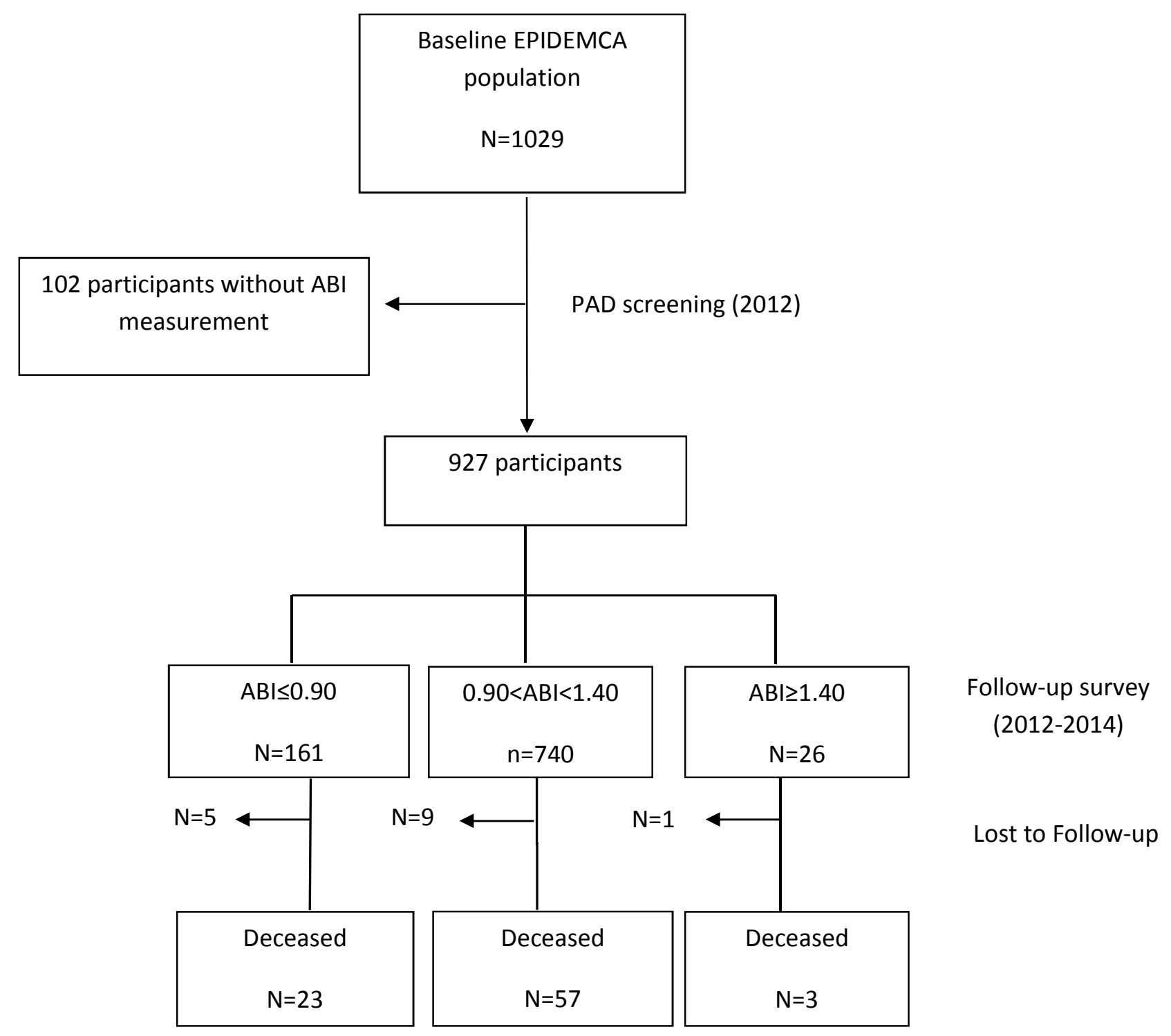

Figure 1: Flow chart of participant selection, EPIDEMCA-FU, Congo, 2012-2014. 
Table 1: Description of baseline characteristics of 927 participants according to ABI group, EPIDEMCA-FU, Congo, 2012-2014.

\begin{tabular}{|c|c|c|c|c|c|c|c|c|c|}
\hline & \multicolumn{2}{|c|}{$0.90<\mathrm{ABI}<1.40$} & \multicolumn{2}{|c|}{$\mathrm{ABI} \leq \mathbf{0 . 9 0}$} & \multicolumn{2}{|c|}{$\mathrm{ABI} \geq \mathbf{1 . 4 0}$} & \multicolumn{2}{|c|}{ Total } & \multirow[t]{2}{*}{$p$-value } \\
\hline & $n=740$ & $\mathbf{7 9 . 8 3 \%}$ & $n=161$ & $17.37 \%$ & $\mathrm{n}=26$ & $2.80 \%$ & $\mathbf{N}=927$ & $100 \%$ & \\
\hline \multicolumn{10}{|l|}{$\begin{array}{l}\text { Sociodemographic } \\
\text { characteristics }\end{array}$} \\
\hline \multicolumn{10}{|l|}{ Age $($ year $)(m v=0)$} \\
\hline$[65-70[$ & 271 & 36.62 & 39 & 24.22 & 7 & 26.92 & 317 & 34.20 & \\
\hline$[70-75[$ & 194 & 26.22 & 45 & 27.95 & 6 & 23.08 & 245 & 26.43 & \\
\hline$[75-80[$ & 148 & 20.00 & 31 & 19.25 & 5 & 19.23 & 184 & 19.85 & 0.009 \\
\hline$[80-85[$ & 80 & 10.81 & 31 & 19.25 & 7 & 26.92 & 118 & 12.73 & \\
\hline$\geq 85$ & 47 & 06.35 & 15 & 09.32 & 1 & 03.85 & 63 & 06.80 & \\
\hline Female sex $(\mathrm{mv}=0)$ & 444 & 60.00 & 112 & 69.57 & 13 & 50.00 & 569 & 61.38 & 0.038 \\
\hline Primary education $(m v=1)$ & 121 & 16.37 & 14 & 08.70 & 5 & 19.28 & 140 & 15.12 & 0.040 \\
\hline Urban residency $(\mathrm{mv}=0)$ & 336 & 45.41 & 91 & 56.52 & 12 & 46.15 & 439 & 47.36 & 0.037 \\
\hline \multicolumn{10}{|l|}{ Clinical characteristics } \\
\hline \multicolumn{10}{|l|}{ Cognitive status $(\mathrm{mv}=100)$} \\
\hline Normal & 595 & 89.61 & 117 & 84.78 & 22 & 88.00 & 734 & 88.75 & \\
\hline MCI & 40 & 06.02 & 11 & 07.97 & 1 & 04.00 & 52 & 06.29 & 0.463 \\
\hline Dementia & 29 & 04.37 & 10 & 07.25 & 2 & 08.00 & 41 & 04.96 & \\
\hline Hypercholesterolemia 'mv=162) & 65 & 10.57 & 23 & 17.97 & 2 & 09.09 & 90 & 11.76 & 0.057 \\
\hline Hypertension $^{\mathbf{a}}(\mathrm{mv}=0)$ & 494 & 66.70 & 129 & 80.12 & 12 & 46.15 & 635 & 68.05 & $<0.001$ \\
\hline Diabetes $(\mathrm{mv}=5)$ & 78 & 10.58 & 18 & 11.32 & 5 & 19.23 & 101 & 10.95 & 0.377 \\
\hline \multicolumn{10}{|l|}{ BMI $\left(\mathbf{k g} / \mathbf{m}^{2}\right)(\mathrm{mv}=24)$} \\
\hline $\mathrm{BMI}<18.5$ & 213 & 29.38 & 48 & 31.58 & 11 & 42.31 & 272 & 30.12 & \multirow{4}{*}{0.057} \\
\hline $18.5 \leq \mathrm{BMI} \leq 24.9$ & 388 & 53.52 & 65 & 42.76 & 10 & 38.46 & 463 & 51.27 & \\
\hline $25.0 \leq \mathrm{BMI} \leq 29.9$ & 87 & 12.00 & 24 & 15.79 & 3 & 11.54 & 114 & 12.62 & \\
\hline$\geq 30$ & 37 & 05.10 & 15 & 09.87 & 2 & 07.69 & 54 & 05.98 & \\
\hline $\begin{array}{l}\text { History of myocardial infarction } \\
{ }^{a}(\mathrm{mv}=5)\end{array}$ & 46 & 06.25 & 20 & 12.50 & 1 & 03.85 & 67 & 07.27 & 0.026 \\
\hline Abdominal obesity ${ }^{a}(m v=45)$ & 487 & 68.79 & 77 & 52.03 & 20 & 76.92 & 584 & 66.21 & $<0.001$ \\
\hline \multicolumn{10}{|l|}{ Lifestyle } \\
\hline Alcohol use $^{\text {a }}(\mathrm{mv}=8)$ & 132 & 17.84 & 24 & 14.92 & 6 & 23.08 & 162 & 17.48 & 0.484 \\
\hline Smoking ${ }^{a}(m v=5)$ & 133 & 18.05 & 37 & 23.27 & 6 & 23.08 & 179 & 19.06 & 0.274 \\
\hline
\end{tabular}

ABI: Ankle Brachial Index; BMI: Body Mass Index; MCI: mild cognitive impairment; mv: missing value. ${ }^{\mathrm{a} O m i t t e d ~ c a t e g o r y ~ f o r ~ d i c h o t o m i c ~ v a r i a b l e s . ~}$ 
Table 2: Association between $\mathrm{PAD}(\mathrm{ABI} \leq 0.90)$ and all-cause mortality after a 2-year follow-up, EPIDEMCA-FU, Congo, 2012-2014.

\begin{tabular}{|c|c|c|c|c|c|c|}
\hline & \multicolumn{2}{|c|}{ Initial model } & \multicolumn{4}{|c|}{ Final multivariate model } \\
\hline & HR & 95\% CI & $p$-value & HR & $95 \% \mathrm{CI}$ & $p$-value \\
\hline \multicolumn{7}{|l|}{ Age } \\
\hline$[65-70[$ & 1 & Reference & \multirow{5}{*}{$<0.001$} & 1 & Reference & \\
\hline$[70-75[$ & 1.14 & $0.61-2.17$ & & 0.84 & $0.29-2.37$ & 0.746 \\
\hline$[75-80[$ & 0.87 & $0.41-1.86$ & & 0.78 & $0.26-2.34$ & 0.660 \\
\hline$[80-85[$ & 2.91 & $1.60-5.33$ & & 1.64 & $0.57-4.68$ & 0.034 \\
\hline$>85$ & 3.41 & $1.66-6.97$ & & 2.14 & $1.26-6.14$ & 0.066 \\
\hline \multicolumn{7}{|l|}{ Sex } \\
\hline Men & 1 & Reference & \multirow{2}{*}{0.010} & 1 & Reference & \\
\hline Women & 0.56 & $0.36-0.86$ & & 0.37 & $0.19-0.72$ & 0.003 \\
\hline \multicolumn{7}{|l|}{ Cognitive status } \\
\hline Normal & 1 & Reference & & 1 & Reference & \\
\hline MCI & 1.13 & $0.45-2.82$ & 0.003 & 1.56 & $0.53-4.55$ & 0.367 \\
\hline Dementia & 3.59 & $1.88-6.85$ & & 2.73 & $1.15-8.03$ & 0.007 \\
\hline \multicolumn{7}{|l|}{ Residency area } \\
\hline Rural residency & 1 & Reference & & & & \\
\hline Urban residency & 1.31 & $0.84-2.02$ & 0.223 & & & \\
\hline \multicolumn{7}{|l|}{ ABI } \\
\hline $0.91<\mathrm{ABI}<1.40$ & 1 & Reference & & 1 & Reference & \\
\hline $\mathrm{ABI} \leq 0.90$ & 1.91 & $1.17-3.10$ & 0.042 & 1.86 & $1.04-3.87$ & 0.044 \\
\hline $\mathrm{ABI} \geq 1.40$ & 1.49 & $0.46-4.77$ & & 0.77 & $0.26-2.47$ & 0.240 \\
\hline \multicolumn{7}{|l|}{ BMI $\left(\mathbf{k g} / \mathbf{m}^{2}\right)$} \\
\hline $\mathrm{BMI}<18.5$ & 1 & Reference & & & & \\
\hline $18.5 \leq \mathrm{BMI} \leq 24.9$ & 0.70 & $0.42-1.17$ & & & & \\
\hline $25.0 \leq \mathrm{BMI} \leq 29.9$ & 1.15 & $0.59-2.23$ & 0.372 & & & \\
\hline $\mathrm{BMI} \geq 30$ & 0.71 & $0.25-2.04$ & & & & \\
\hline \multicolumn{7}{|l|}{ Smoking (ref : no) } \\
\hline Yes & 0.70 & $0.37-1.33$ & 0.284 & & & \\
\hline \multicolumn{7}{|l|}{ Alcohol use (ref : no) } \\
\hline Yes & 0.41 & $0.18-0.90$ & 0.027 & 0.51 & $0.29-0.88$ & 0.017 \\
\hline \multicolumn{7}{|l|}{ Hypertension (ref : no) } \\
\hline Yes & 1.42 & $0.86-2.35$ & 0.160 & & & \\
\hline \multicolumn{7}{|l|}{$\begin{array}{l}\text { Hypercholesterolemia } \\
\text { (ref : no) }\end{array}$} \\
\hline Yes & 1.65 & $0.98-2.47$ & 0.065 & & & \\
\hline
\end{tabular}




\section{Diabetes (ref : no)}

Yes

1.59

$0.88-2.88$

0.142

Abdominal obesity

(ref :no)

Yes

$0.93 \quad 0.550-1.56$

0.796

ABI: Ankle Brachial Index; BMI: Body Mass Index; CI: confidence interval; HR: hazard ratio; MCI: mild cognitive impairment. 
Supplementary table 1: Description of 1029 participants according to baseline ABI measurement, EPIDEMCA-FU, Congo, 2012-2014.

\begin{tabular}{|c|c|c|c|c|c|c|c|}
\hline & \multicolumn{2}{|c|}{$\begin{array}{l}\text { Without ABI } \\
\text { measurement }\end{array}$} & \multicolumn{2}{|c|}{$\begin{array}{l}\text { Completed ABI } \\
\text { measurement }\end{array}$} & \multicolumn{2}{|c|}{ Total } & \multirow[t]{2}{*}{$p$-value } \\
\hline & $\mathrm{n}=102$ & $(9.91 \%)$ & $\mathrm{n}=927$ & $(90.08 \%)$ & $\mathrm{N}=1029$ & $(100 \%)$ & \\
\hline \multicolumn{8}{|l|}{ Sociodemographic } \\
\hline \multicolumn{8}{|l|}{ Characteristics } \\
\hline \multicolumn{8}{|l|}{ Age (year) } \\
\hline$[65-70[$ & 24 & 23.52 & 317 & 34.20 & 340 & 33.04 & \multirow{5}{*}{0.008} \\
\hline$[70-75[$ & 21 & 20.58 & 245 & 26.43 & 266 & 25.85 & \\
\hline$[75-80[$ & 22 & 21.57 & 184 & 19.85 & 206 & 20.02 & \\
\hline$[80-85[$ & 20 & 19.61 & 118 & 12.73 & 138 & 13.41 & \\
\hline$\geq 85$ & 15 & 14.72 & 63 & 06.80 & 78 & 07.68 & \\
\hline Female sex & 57 & 55.88 & 569 & 61.38 & 629 & 60.84 & 0.280 \\
\hline Urban residency & 61 & 59.80 & 439 & 47.36 & 500 & 48.59 & 0.017 \\
\hline $\begin{array}{l}\text { Education (6years of education } \\
\text { completed) }\end{array}$ & 16 & 16.00 & 140 & 15.12 & 156 & 15.20 & 0.816 \\
\hline \multicolumn{8}{|l|}{ Clinical Characteristics } \\
\hline \multicolumn{8}{|l|}{ Cognitive status $^{b}$} \\
\hline Normal & 57 & 68.67 & 734 & 88.75 & 791 & 86.92 & \multirow{3}{*}{$<0.001$} \\
\hline MCI & 4 & 48.82 & 52 & 06.26 & 56 & 06.15 & \\
\hline Dementia & 22 & 26.51 & 4 & 4.96 & 63 & 06.92 & \\
\hline \multicolumn{8}{|l|}{ BMI $\left(\mathrm{kg} / \mathrm{m}^{2}\right)^{\mathrm{b}}$} \\
\hline $\mathrm{BMI}<18.5$ & 17 & 32.08 & 272 & 30.12 & 289 & 30.23 & \multirow{4}{*}{0.021} \\
\hline $18.5 \leq \mathrm{BMI} \leq 24.9$ & 20 & 37.74 & 463 & 51.27 & 483 & 50.52 & \\
\hline $25.0 \leq \mathrm{BMI}<29.9$ & 7 & 13.21 & 114 & 12.62 & 121 & 12.66 & \\
\hline $\mathrm{BMI} \geqq 30$ & 9 & 16.98 & 54 & 05.98 & 63 & 06.59 & \\
\hline Abdominal obesity ${ }^{b}$ & 25 & 46.30 & 298 & 33.79 & 323 & 34.51 & 0.061 \\
\hline Hypercholesterolemia ${ }^{b}$ & 4 & 06.15 & 90 & 11.76 & 94 & 11.33 & 0.171 \\
\hline Hypertension & 59 & 57.84 & 635 & 68.50 & 694 & 67.44 & 0.029 \\
\hline Diabetes $^{b}$ & 13 & 15.85 & 101 & 10.95 & 114 & 11.35 & 0.180 \\
\hline \multicolumn{8}{|l|}{ Lifestyle } \\
\hline Smoking ${ }^{b}$ & 15 & 15.15 & 179 & 19.35 & 194 & 18.95 & 0.311 \\
\hline Alcohol use $^{b}$ & 24 & 23.53 & 162 & 17.48 & 186 & 18.08 & 0.132 \\
\hline
\end{tabular}




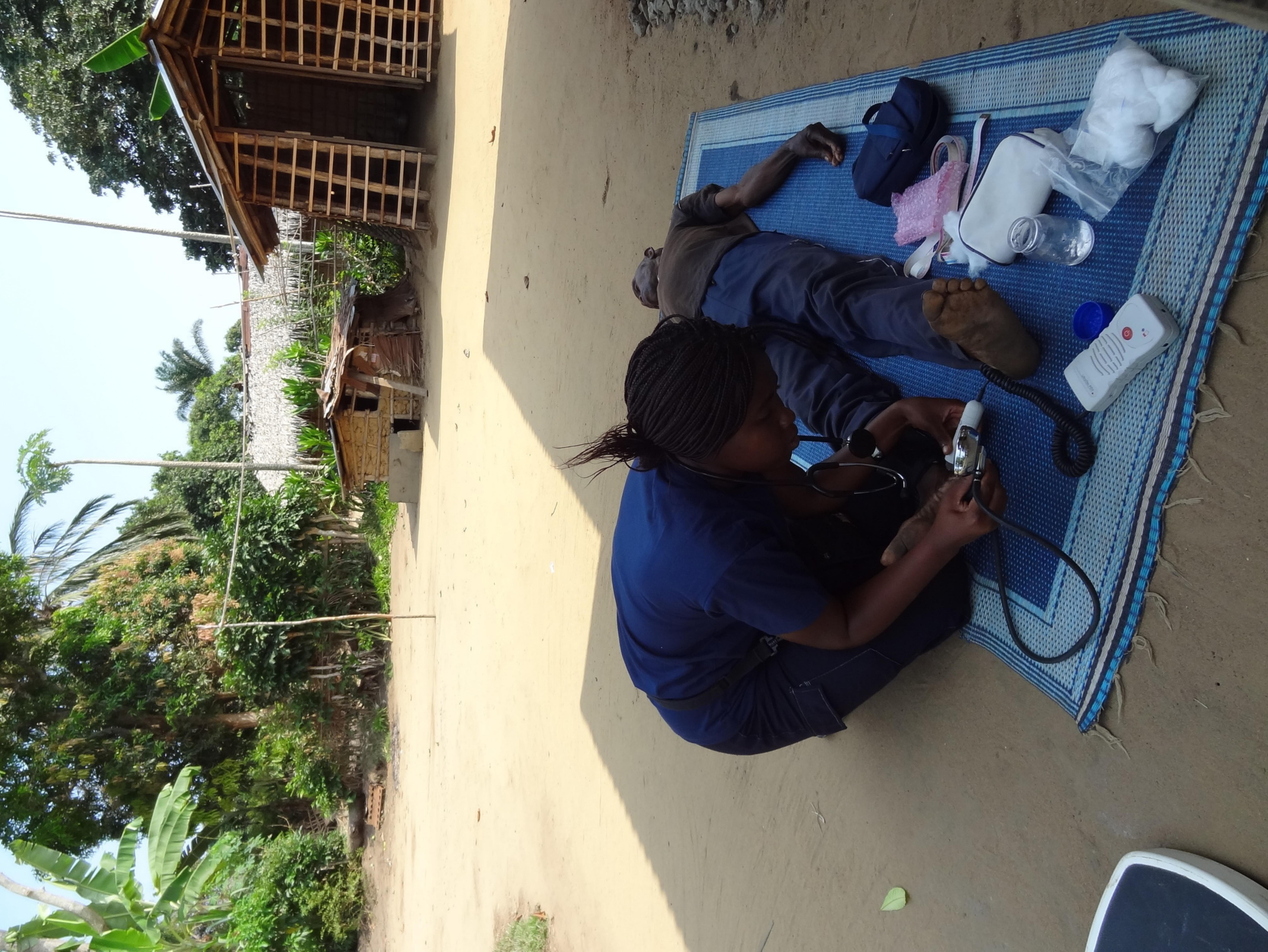

